\title{
Amurubicinol-induced eotaxin-3 expression in human NCI-H69 small cell lung carcinoma cells
}

\author{
MASAMI NIIYA ${ }^{1}$, KENJI NIIYA ${ }^{2}$, MISAKO SHIBAKURA ${ }^{3}$, NOBORU ASAUMI ${ }^{1}$, \\ CHIKAMASA YOSHIDA ${ }^{1}$ and MITSUNE TANIMOTO ${ }^{1}$ \\ ${ }^{1}$ Department of Medicine II, Faculty of Medicine, Okayama University Medical School, Okayama; \\ ${ }^{2}$ Kasaoka city Hospital, Kasaoka; ${ }^{3}$ Faculty of Health Sciences, Okayama University Medical School, Okayama, Japan
}

Received September 12, 2005; Accepted November 11, 2005

\begin{abstract}
We previously demonstrated the doxorubicininduced expression of urokinase-type plasminogen activator (uPA), interleukin-8 (IL-8), monocyte chemoattractant protein-1 (MCP-1) and tumor necrosis factor- $\alpha$ in human RCK8 lymphoma cells and NCI-H69 small cell lung carcinoma cells in which reactive oxygen species might be involved. Amurubicin hydrochloride (AMR), a novel derivative drug of doxorubicin, was recently introduced to clinical practice for treatment of lung cancer in Japan. Therefore, we investigated the effects of AMR on the expression of uPA and chemokines in NCI-H69 cells. AMR and its active form, amurubicinol hydrochloride $(\mathrm{AMROH})$, both induced the expression of uPA, IL-8 and MCP-1 in H69 cells in a dose-dependent manner. When the cultured supernatant obtained from AMRtreated H69 cells was subcutaneously injected into rabbits, migration of a significant number of eosinophils was observed around the injected site. Antigen levels of eotaxin-3, a major migration-factor of eosinophils, were increased in $\mathrm{AMROH}-$ treated cells in parallel with the mRNA levels. The induction was observed below the clinically achievable concentration
\end{abstract}

Correspondence to: Dr Masami Niiya, Department of Medicine II, Faculty of Medicine, Okayama University Medical School, 2-5-1 Shikatacho, Okayama 700-8558, Japan

E-mail: niiya7@yahoo.co.jp

Abbreviations: AMR, amurubicin hydrochloride; AMROH, amurubicinol hydrochloride; ERK, extracellular signal-regulated kinase; GAPDH, glyceraldehydes-3-phophate dehydrogenase; IL, interleukin; JNK, c-jun N-terminal protein kinase; MAP, mitogenactivated protein; MCP, monocyte chemoattractant protein; MIP, macrophage inflammatory protein; MTT, 3-(4,5-Dimethylthiazol2-yl)-2,5-diphenyl tertrazolium bromide; RANTES, regulated upon activation, normal T-cell expressed and secreted; ROS, reactive oxygen species; SCLC, small cell lung carcinoma; uPA, urokinasetype plasminogen activator

Key words: amurubicin, amurubicinol, eotaxin-3, small cell lung carcinoma cells, urokinase-type plasminogen activator, interleukin-8, monocyte chemoattractant protein-1 of AMR or AMROH. Thus, the simultaneous induction of uPA, IL-8, MCP-1 and eotaxin-3 may play a role in the pharmacological action of AMR through induction of the interaction between proinflammatory cells and lung carcinoma cells.

\section{Introduction}

Doxorubicin induces apoptosis of human malignant cells possibly through generating reactive oxygen species (ROS) in the cells (1). Doxorubicin is the most widely used anticancer agent and is a key drug for the treatment of malignant lymphoma and small cell lung cancer (SCLC) $(2,3)$. We have previously reported doxorubicin-induced urokinase-type plasminogen activator (uPA) expression in two human malignant cell lines, RC-K8 lymphoma cells and NCI-H69 SCLC cells (4). The maximum induction of these factors was observed at 'sublethal' concentrations of doxorubicin where cell-growth was slightly inhibited. Furthermore, we also demonstrated doxorubicin-induced interleukin-8 (IL-8), monocyte chemoattractant protein-1 (MCP-1) (5) and tumor necrosis factor- $\alpha$ (TNF- $\alpha$ ) expressions (6) in human RC-K8 lymphoma cells and NCI-H69 SCLC cells.

Amurubicin hydrochloride (AMR) is a novel, completely synthetic 9-aminoanthracycline derivative. Amurubicinol hydrochloride (AMROH), the C-13 alcohol metabolite of AMR, is the active form of AMR. AMROH was detected as a major metabolite in the tumor tissue of AMR-treated mice (7). This metabolite may be in large part account for the biological activity of AMR in vivo also in humans and its anti-tumor activity appeared to be 10 times stronger than that of AMR (8). Achievable plasma levels of AMR and AMROH are $20 \mu \mathrm{M}$ and $2 \mu \mathrm{M}$, respectively, and the half-life of AMR is $1.6 \mathrm{~h}$, and that of AMROH is $6.75 \mathrm{~h} \mathrm{(7).} \mathrm{Both} \mathrm{are}$ potent inhibitors of topoisomerase II, and the anti-tumor activity of AMR was shown to be superior to that of doxorubicin (9). uPA, IL-8 and MCP-1 all play significant roles in tumor-growth and invasion because uPA could not only dissolve extracellular matrix but activate IL-8; and IL-8 and MCP-1 are very active chemokines that chemoattract leukocytes and monocytes/macrophages, respectively (10-13). We investigated the effects of AMR and $\mathrm{AMROH}$ on the expression of uPA, IL-8 and MCP-1 in H69 cells, and confirmed the induction of uPA, IL- 8 and MCP-1 by ELISA, 

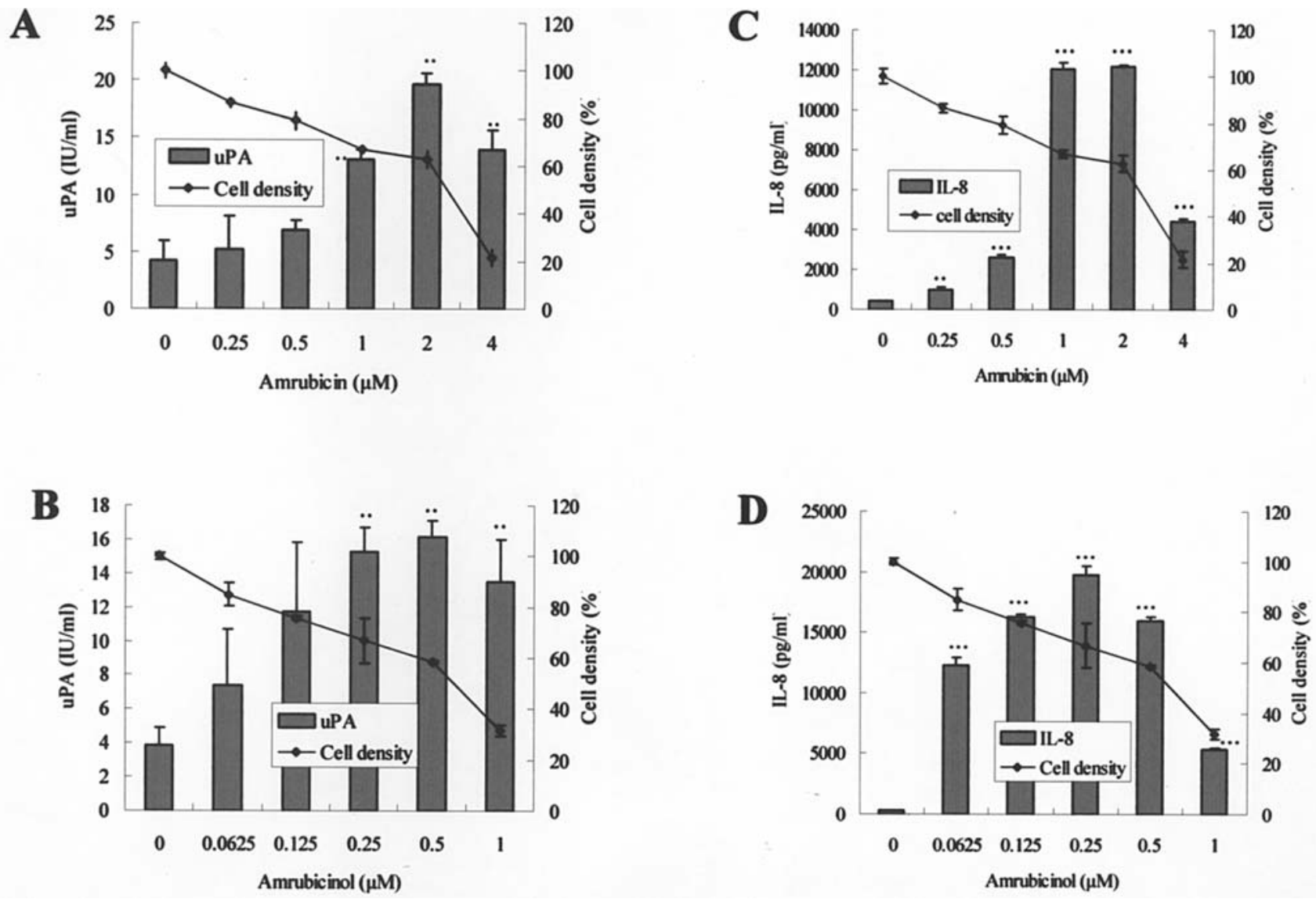

Figure 1. Effects of AMR and AMROH on uPA and IL-8 accumulation and cell density in H69 cells. H69 cells were cultured in the presence of varying concentrations of AMR (A and C) and AMROH (B and D) for $24 \mathrm{~h}$, and uPA activity (A and B), IL-8 levels (C and D) and cell density were measured using a synthetic uPA substrate (S-2444) and MTT assay, respectively, as described in Materials and methods. Each experiment was conducted as least twice in triplicate, and results were reproducible. Columns and closed circles indicate uPA or IL- 8 levels and cell density, respectively. Mean \pm SE of triplicate values are shown. ${ }^{* * *} \mathrm{p}<0.001$ and ${ }^{* *} \mathrm{p}<0.01$ using Student's t-test compared to values obtained from AMR- or AMROH-treated cells.

Northern blotting and RNase protection assay. To further clarify the significance of the induction of uPA, IL-8 and MCP-1, we performed an in vivo study by subcutaneously injecting the cultured supernatant obtained from AMR or AMROH-treated cells into rabbits. Microscopic examination revealed the migration of a significant number of proinflammatory cells, especially eosinophils, around the injection site. The expression of eotaxins, major eosinophil chemoattrantants, was examined in AMR-treated cells. Here, we demonstrate the AMR-induced eotaxin-3 expression in H69 cells.

\section{Materials and methods}

Materials, cell lines and culture. AMR and AMROH were kindly provided by Sumitomo Pharmaceuticals (Osaka, Japan). Human NCI-H69 (ATCC HBT-119) SCLC cells were grown in RPMI-1640 culture medium supplemented with $10 \%(\mathrm{v} / \mathrm{v})$ heat-inactivated fetal bovine serum (Whittaker Bioproducts, Walkersville, MD, USA), $100 \mathrm{U} / \mathrm{ml}$ penicillin and $100 \mu \mathrm{g} / \mathrm{ml}$ streptomycin. Cells were washed once with phosphatebuffered saline and resuspended in serum-free RPMI-1640 (at approximately 1-2x106/ml). Cells were exposed to AMR or AMROH for $1 \mathrm{~h}$ because AMR and AMROH are usually administered to patients by an intravenous infusion and therefore they rapidly disappear from the blood stream. Cells washed once with serum-free RPMI-1640 were further cultured in serum-free RPMI-1640 in a 24 -well culture plate $\left(1 \mathrm{ml} /\right.$ well) or 6 -well culture plate $(5 \mathrm{ml} /$ well $)$ in a $5 \% \mathrm{CO}_{2}$ incubator. Cell growth was estimated by the colorimetric 3(4,5-dimethylthiazol-2-yl)-2,5-diphenyl tertrazolium bromide (MTT) assay for mitochondrial dehydrogenase enzyme activity as described by Mosmann (14), and results were expressed as cell density (\% relative to untreated controls). uPA activities in the cultured supernatant obtained $24 \mathrm{~h}$ after exposure to AMR or AMROH were measured using a synthetic uPA substrate, S-2444 (15) and a plasminogen-containing fibrin plate (fibrin zymography) as previously described (16). Cultured supernatants were collected and stored at $-80^{\circ} \mathrm{C}$ before use.

ELISA for IL-8 and eotaxin-3. After stimulating with varying concentrations of AMR or AMROH, the cultured supernatant from each cell type $\left(1.0 \times 10^{6} / \mathrm{ml}\right)$ was collected and processed for IL-8 and eotaxin-3 quantification by an ELISA kit (R\&D Systems, MN, USA).

Northern blot analysis and RT-PCR. Eotaxin-3 mRNA levels were detected by Northern blotting. Briefly, cells were exposed to AMROH for $1 \mathrm{~h}$, washed once with the RPMI-1640 culture medium, and further cultured for varying times. Total RNA was isolated by the acid guanidinium thiocyanate-phenolchloroform method, and $10 \mu \mathrm{g}$ of total RNA was subjected to Northern blot analysis as described by Sambrook et al (17). A 


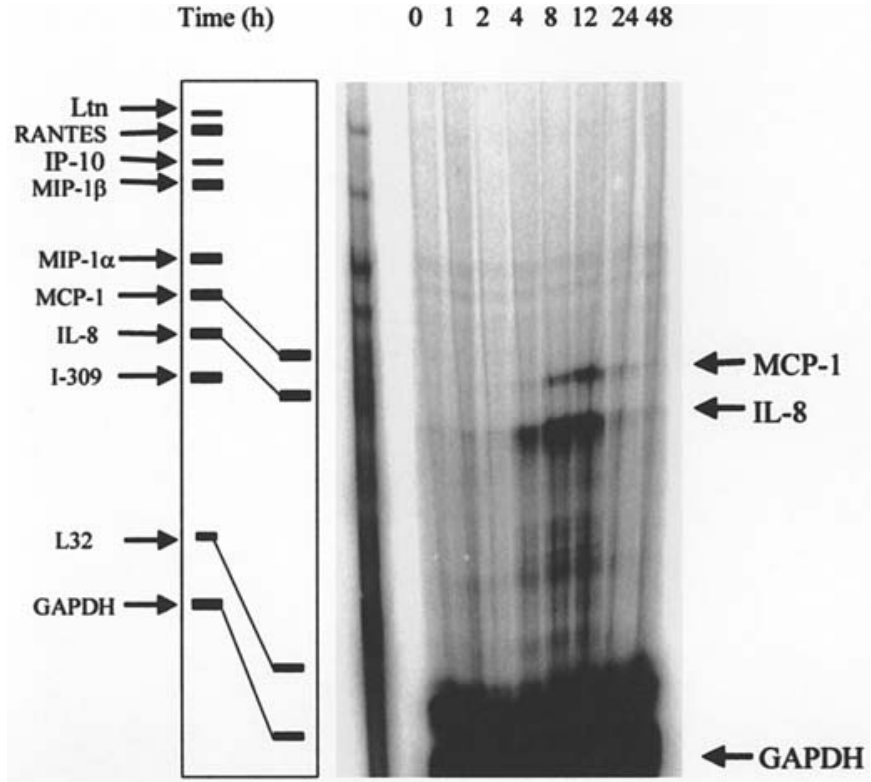

Figure 2. RNase protection assay before and after AMROH stimulation in H69 cells. Total RNA $(10 \mu \mathrm{g})$ isolated from $\mathrm{H} 69$ cells exposed to $0.5 \mu \mathrm{M}$ AMROH for varying hours was further purified to mRNA using an oligo(dT)cellulose column and subjected to RNase protection assay, as described in Materials and methods. Lanes on the left illustrate the positions of radiolabeled antisense probe and the remaining 'RNase protected' probes that were resolved on denaturing polyacrylamide gels.

cDNA probe for eotaxin-3 was labeled with 32P-dCTP by a random primed DNA labeling technique. mRNA levels were quantified by counting radioactivity using a BAS-2000 imaging analyzer (Fuji-film, Tokyo, Japan). To control the differences in RNA sample loading, filters were rehybridized with a radiolabeled $B$-actin cDNA probe.

RT-PCR was performed as follows: Briefly, total RNA (2 $\mu \mathrm{g})$ was reverse-transcribed with the SuperScript Preamplication System (Life Technologies, Rockville, MD, USA) using oligo(dT) primers according to the manufacturer's instructions. Aliquots $(1 \mu \mathrm{g})$ of the reverse-transcribed cDNA were subjected to PCR. The sequences of eotaxin, eotaxin-2, eotaxin-3 and regulated upon activation, normal T-cell expressed and secreted (RANTES) obtained from the studies of Terada et al (18), Dulkys et al (19), Hoeck et al (20) and Tokunaga et al (21), respectively, were used to design primers. The sequences of sense and antisense primers for eotaxin were 5'-CCTCTCACGCCAAAGCTCACA-3', and 5'-TAGGCAA CACTCAGGCTCTGG-3', corresponding to nucleotides 63-83 and 437-417, respectively (product size $375 \mathrm{bp}$ ). The sequences of sense and antisense primers for eotaxin-2 were 5'-CCATA GTAACCAGCCTTC-3', and 5'-CAGGTTCTTCATGTAC CTC-3', corresponding to nucleotides 17-34 and 267-249, respectively (product size $251 \mathrm{bp}$ ). The sequences of sense and antisense primers for eotaxin-3 were 5'-GCCTGATTTG CAGCATCATGATGG-3', and 5'-CGGATGACAATTCA GCTGAGTCAC-3', corresponding to nucleotides 11-34 and 332-309, respectively (product size $322 \mathrm{bp}$ ). The sequences of sense and antisense primers for glyceraldehydes-3-phophate dehydrogenase (GAPDH) were 5'-CGGATTTGGTCGTAT TGG-3', and 5'-AGATGGTGATGGGATTTC-3', corresponding to nucleotides 87-104 and 289-272, respectively (product size $203 \mathrm{bp}$ ). PCR for eotaxin was performed with
30 cycles of a heat-denaturing step at $94^{\circ} \mathrm{C}$ for $2 \mathrm{~min}$, a primer annealing step at $55^{\circ} \mathrm{C}$ for $2 \mathrm{~min}$ and a strand elongation step at $72^{\circ} \mathrm{C}$ for $2 \mathrm{~min}$. PCR for eotaxin- 2 was performed with 40 cycles of a heat-denaturing step at $95^{\circ} \mathrm{C}$ for $30 \mathrm{sec}$, a primer annealing step at $58^{\circ} \mathrm{C}$ for $30 \mathrm{sec}$ and a strand elongation step at $72^{\circ} \mathrm{C}$ for $1 \mathrm{~min}$. PCR for eotaxin- 3 was performed with 30 cycles of a heat-denaturing step at $94^{\circ} \mathrm{C}$ for $1 \mathrm{~min}$, a primer annealing step at $55^{\circ} \mathrm{C}$ for $1 \mathrm{~min}$ and a strand elongation step at $72^{\circ} \mathrm{C}$ for $1 \mathrm{~min}$. PCR for GAPDH was performed with 25 cycles of a heat-denaturing step at $94^{\circ} \mathrm{C}$ for $1 \mathrm{~min}$, a primer annealing step at $50^{\circ} \mathrm{C}$ for $30 \mathrm{sec}$ and a strand elongation step at $72^{\circ} \mathrm{C}$ for $1 \mathrm{~min}$. PCR products $(10 \mu \mathrm{g})$ were electrophoresed on $2 \%$ agarose gel containing $0.5 \mu \mathrm{g} / \mathrm{ml}$ ethidium bromide. Loading was equalized to the internal control mRNA (GAPDH) to give equivalent signals. Gels were illuminated with UV light and photographed using Polaroid film (Polaroid, Herfordshire, UK).

RNase protection assay. Specific detection for mRNA of the chemokine family was performed using the hCK-5 Multi-probe template set (RiboQuant; Pharmingen, San Diego, CA), which contains templates for Ltn, RANTES, IP-10, macrophage inflammatory protein (MIP)-1 $\alpha$, MIP-1ß, MCP-1, IL- 8 and I-309, in addition to the housekeeping gene products, L32 and GAPDH. In brief, antisense RNA probes were generated from the DNA templates included in the above assay kit using T7 DNA-dependent RNA polymerase in the presence of $\left[\alpha{ }^{-32} \mathrm{P}\right] \mathrm{UTP}$ (specific activity 3,000 Ci/mmol; ICN, Irvine, CA). Labeled probes were hybridized with total RNA $(10 \mu \mathrm{g})$ overnight at $56^{\circ} \mathrm{C}$. Unhybridized RNA was digested with RNase according to Pharmingen's instruction manual. RNaseprotected probes were resolved on a denaturing $5 \%$ polyacrylamide gel. The gel was dried and visualized using the BAS-2000 imaging analyzer.

Statistical analysis. Statistical analysis was performed on a DOS/V computer (NEC Computer, Tokyo, Japan). Values were expressed as the mean \pm SE. Statistical significance was determined using the Student's t-test to compare unpaired data.

\section{Results}

Migration of eosinophils around the injection site of the cultured supernatant of AMR-treated cells. We investigated the effects of AMR on UPA, IL-8 and MCP-1 expression in H69 cells. Similarly to the case of doxorubicin, either AMR or AMROH induced UPA and IL-8 in a dose-dependent manner, and the peak induction was observed at a sublethal concentration of each reagent (Fig. 1A-D). Both AMR and AMROH increased uPA accumulation approximately 4-fold, and IL-8, 20-fold, respectively. AMR and AMROH themselves did not directly affect the enzymatic activity of uPA when mixed with standard uPA (Green Cross, Osaka, Japan) in RPMI-1640 medium. The RNase protection assay using human chemokine probes performed as previously described in our study (5) revealed the induction of IL-8 and MCP-1 genes (Fig. 2). To clarify the in vivo effects of the cultured supernatant from AMROH-treated cells, we injected subcutaneously the cultured supernatants from AMROHtreated and non-treated cells into rabbits. H69 cells were 
$\mathbf{A}$

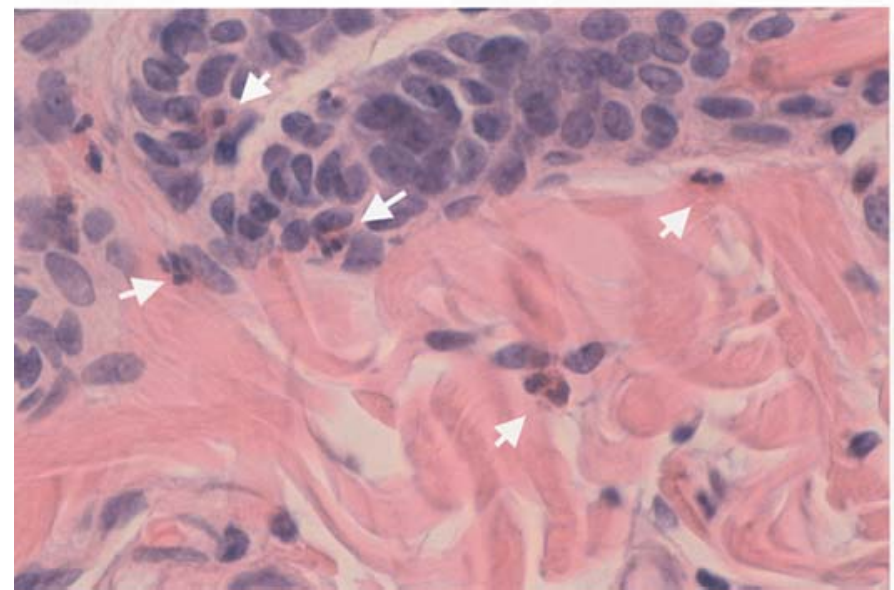

B

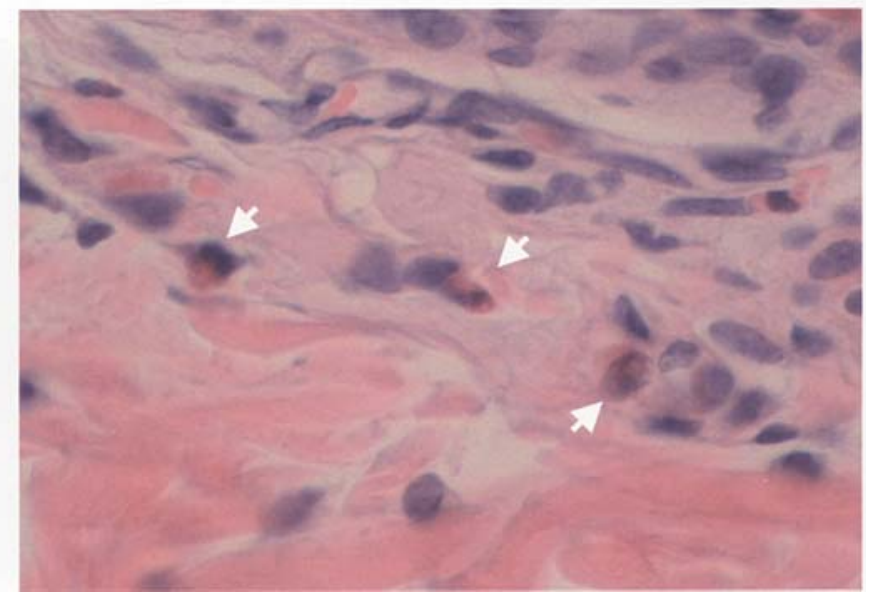

Figure 3. Migration of eosinophils around the injection site of the cultured supernatant from AMROH-treated H69 cells. Specimens taken from the injected site of the cultured supernatant of AMR (A)- or AMROH (B)-treated cells were fixed in formaldehyde and embedded in paraffin. The slides were stained with $\mathrm{H} \& \mathrm{E}$ and visualized by optical microscope. Original magnifications, $\mathrm{x} 400$ (A and B). Arrows indicate migrated eosinophils.

$\mathbf{A}$

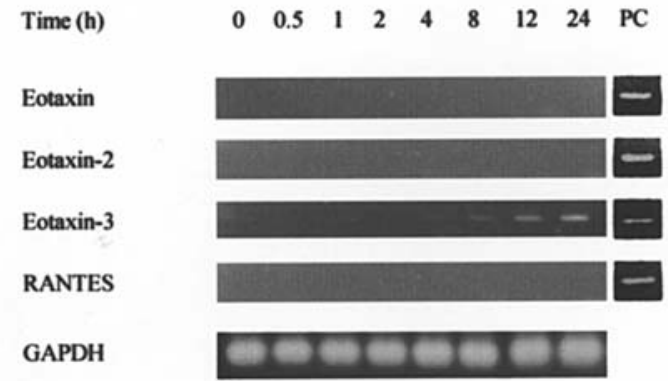

B

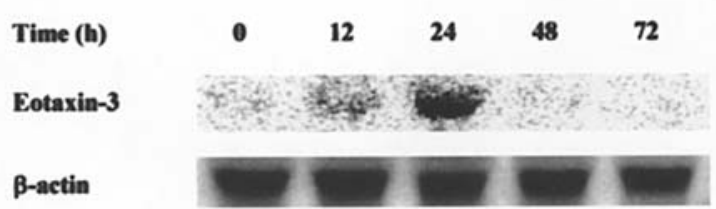

exposed to $0.5 \mu \mathrm{M}$ AMROH for $1 \mathrm{~h}$, and after washing, further cultured for $23 \mathrm{~h}$ in a $5 \% \mathrm{CO}_{2}$ incubator. The cultured supernatant was collected and subcutaneously injected into rabbits and specimens were obtained $24 \mathrm{~h}$ after injection by small incision. Microscopic examination revealed the migration of a significant number of eosinophils rather than lymphocytes, neutrophils and monocytes around the injection site (Fig. 3). No significant migration of inflammatory cells including eosinophils was noted around the injection site of the control supernatant.

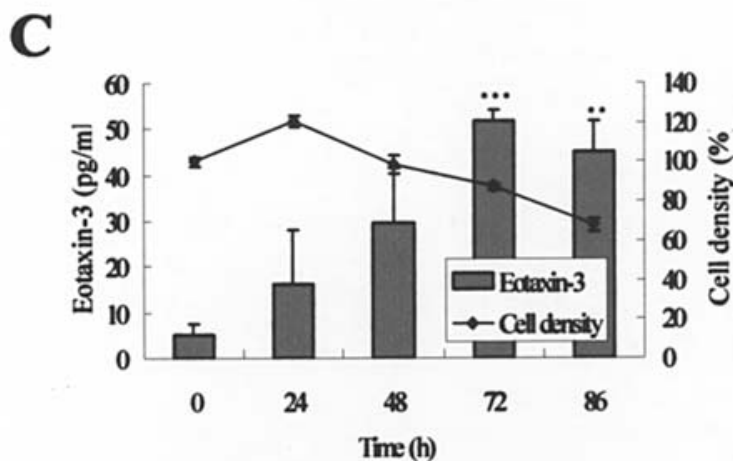

Figure 4. Effects of AMROH on the mRNA and antigen levels of eotaxin-3 in H69 cells. (A) Eotaxin, eotaxin-2, eotaxin-3 and RANTES mRNA levels qualitatively measured by RT-PCR in H69 cells. Amplified fragments obtained with PCR were analyzed, and GAPDH was used as an internal control. PC, positive control. (B) Time-course of AMROH-induced eotaxin-3 mRNA levels in H69 cells. Eotaxin-3 mRNA levels were measured by Northern blotting. Total RNA ( $20 \mu \mathrm{g}$ each) was extracted from H69 cells at the time shown following exposure to $0.5 \mu \mathrm{M}$ AMROH. A $\beta$-actin probe was used as an internal control. (C) Eotaxin-3 antigen levels in AMROHtreated $\mathrm{H} 69$ cells. $\mathrm{H} 69$ cells were cultured in the presence of AMROH for the time shown in the figure, and eotaxin-3 antigen levels and cell density were measured by ELISA and MTT assay, respectively. Each experiment was conducted at least twice in triplicate. Columns and closed circles indicate eotaxin-3 antigen levels and cell density, respectively. Mean \pm SE of triplicate values are shown.

AMROH-induced eotaxin-3 gene expression. Eotaxin, eotaxin-2, eotaxin-3 and RANTES are known to be migration factors of eosinophils. We investigated their gene expressions in AMROH-treated H69 cells by Northern blotting and RTPCR. The peak induction of UPA and IL- 8 by AMROH was observed at $0.25-0.5 \mu \mathrm{M}$ (Fig. 1B and D), and, therefore, in this experiment, $\mathrm{H} 69$ cells were stimulated with $0.5 \mu \mathrm{M}$ of AMROH. RT-PCR revealed the induction of eotaxin-3 gene, but not eotaxin, eotaxin-2 or RANTES, in AMROH-treated cells 24 h after stimulation (Fig. 4A). Northern blot analysis 
also revealed $\mathrm{AMROH}$-induced eotaxin-3, and the peak was at $24 \mathrm{~h}$ after exposure (Fig. 4B).

We also measured the antigen levels of eotaxin- 3 in the cultured supernatant by ELISA. AMROH increased eotaxin-3 accumulation in a time-dependent manner as shown in Fig. 4C. This was also dose-dependent (data not shown).

Additionally, we examined the implication of mitogenactivated protein (MAP) kinases in the induction, since we reported the involvement of extracellular signal-regulated kinase (ERK) 1/2 and p38 MAP kinase in doxorubicin-induced uPA expression (22). Treatment with AMROH resulted in the induction of phosphorylation of all three MAP kinases, i.e., ERK 1/2, p38 MAP kinase and c-jun N-terminal protein kinase (JNK) (data not shown). Furthermore, it was suggested by the examination using respective-specific inhibitors against the three MAP kinases that ERK1/2 and p38 MAPK, but not JNK, were implicated in AMROH-induced uPA expression in $\mathrm{H} 69$ cells (data not shown). An antioxidant, pyrrolidine dithiocarbamate $(1 \mathrm{mM})$, inhibited the AMROH-induced uPA accumulation (data not shown), suggesting the involvement of ROS in AMROH-induced UPA expression. These results were very similar in the case of doxorubicin $(4,22)$.

\section{Discussion}

Eotaxin-3 is a member of the family of CC-chemokines and the most potent chemoattractant for ensionophils. Other important eosinophil chemoattractant cytokines known are IL-5, IL-8, eotaxin, eotaxin-2, RANTES, MCP-3, MCP-4 and TNF- $\alpha$ (23). As shown in this study, it is clear that AMROH induces eotaxin-3 expression as well as IL-8 in a timedependent fashion in human H69 SCLC cells. Chemoattraction of eosinophils is mainly mediated via the chemokine receptor CCR3. This seven-transmembrane-spanning G protein-coupled receptor is predominantly expressed on eosinophils. CCR3 binds a number of CC-chemokines such as eotaxin and eotaxin-3 $(24,25)$. Thus, eotaxin-3 must have been involved in the migration of eosinophils when the cultured supernatant was injected into rabbit skin in this experiment. CCR3 is also detected on the cell surface of basophils and a subset of Th2 type T lymphocytes (26-28) and, therefore, eotaxin-3 induced by the stimulation with AMROH might chemoattract basophils and Th2 type T lymphocytes, although basophils and Th2 type T lymphocytes were not so significantly migrated in the injection site. Activated eosinophils possess phagocytic capacity, but their main killing mechanism is the release of toxic granule proteins and production of oxygen-free radicals (23). Basophils could release chemical mediators such as IL-4 into the extracellular space of tissues or blood stream and play a significant role in hypersensitivity, hyperplasia, parasitic infections and other diseases (29). Animal models and clinical studies in humans have indicated an important role of Th2 lymphocytes, producing IL-4, IL-5 and IL-13, in the pathogenesis of allergic disorder (30). It is generally suggested that primary exposure to an allergen leads to activation of Th2 lymphocytes in predisposed individuals and stimulation of IgE synthesis of B lymphocytes, and later exposures cause immediate release of chemical mediators and further activation of Th2 cells (31). uPA receptor is expressed on the cell surface of basophils, and uPA appears to be a potent chemoattractant for basophils (32).

A number of cytokines such as the granulocytemacrophage colony stimulating factor and platelet activating factor have been found to be synthesized and stored in human eosinophils and released from eosinophils. IL-8 could release these cytokines as well as $\operatorname{IgA}$ and $\operatorname{IgG}$ from eosinophils $(33,34)$. Therefore, IL-8 induced by the stimulation with AMR in tumor cells could release these cytokines from eosinophils migrated around tumor tissue.

IL-8 is a member of the CXC chemokine family and acts as a chemoattractant and an activator of neutrophils $(10,11)$, whereas MCP-1 is one of the CC chemokines and functions mainly as a chemoattractant of monocytes/macrophages $(12,13)$. We anticipated the migration of neutrophils and monocytes/macrophages into the injection site of the cultured supernatant because IL- 8 and MCP- 1 were accumulated in the cultured supernatant of AMR-treated H69 cells. However, observation of the skin by microscope revealed the migration of eosinophils rather than other leukocytes. Therefore, the induction of eotaxin-3 may be the most relevant phenomenon in the tumor cell biology after exposure to AMR. We may have to examine whether neutralization of eotaxin-3 in the culture supernatants blocks eosinophil accumulation in rat, and whether expression of eotaxin-3 and accumulation of eosinophils induced by AMR occur in other cell lines or in other in vivo models. We do not yet have direct evidence indicating the involvement of eotaxin-3 in the eosinophilchemoattractive effects of AMROH-treated cultured supernatant, but it may be clarified if a neutralizing antibody against eotaxin- 3 could be obtained.

We have demonstrated here that AMROH markedly induces not only eotaxin-3 but also UPA, IL- 8 and MCP-1 in H69 SCLC cells. Eotaxin-3, uPA, IL-8 and MCP-1 are simultaneously and extensively induced in a certain type of tumor cells by AMROH stimulation and presumably strengthen the anti-tumor effects of AMROH by provoking the interaction between inflammatory/immune cells and tumor cells. Thus, the significance of the AMROH-induced biological active substances would be clarified by future in vivo experiments.

\section{Acknowledgements}

This study was supported in part by Grants-in-Aid (No. 12771476 and No. 14771350) for Encouragement of Young Scientists (M.S.) from the Ministry of Education, Science, Sports and Culture, Japan. Northern blot analysis was carried out in the Radioisotope Center of Okayama University.

\section{References}

1. Muller I, Niethammer D and Bruchelt G: Anthracycline-derived chemotherapeutics in apoptosis and free radical cytotoxicity (Review). Int J Mol Med 1: 491-494, 1998.

2. Fisher RI, Gaynor ER, Dahlberg S, Oken MM, Grogan TM, Mize EM, Glick JH, Coltman CA Jr and Miller TP: Comparison of a standard regimen (CHOP) with three intensive chemotherapy regimens for advanced non-Hodgkin's lymphoma. $\mathrm{N}$ Engl J Med 328: 1002-1006, 1993.

3. Zochbauer-Muller S, Pirker R and Huber H: Treatment of small cell lung cancer patients. Ann Oncol 10 (Suppl 6): 83$91,1999$. 
4. Kiguchi T, Niiya K, Shibakura M, Miyazono T, Shinagawa K, Ishimaru F, Kiura K, Ikeda K, Nakata Y and Harada M: Induction of urokinase-type plasminogen activator by the anthracycline antibiotic in human RC-K8 lymphoma and H69 lung-carcinoma cells. Int J Cancer 93: 792-797, 2001.

5. Shibakura M, Niiya K, Kiguchi T, Kitajima I, Niiya M, Asaumi N, Huh NH, Nakata Y, Harada M and Tanimoto M: Induction of IL-8 and monoclyte chemoattractant protein- 1 by doxorubicin in human small cell lung carcinoma cells. Int J Cancer 103: 380-386, 2003.

6. Niiya M, Niiya K, Kiguchi T, Shibakura M, Asaumi N, Shinagawa K, Ishimaru $\mathrm{F}$, Kiura $\mathrm{K}$, Ikeda $\mathrm{K}$, Ueoka $\mathrm{H}$, et al: Induction of TNF-alpha, UPA, IL-8 and MCP-1 by doxorubicin in human lung carcinoma cells. Cancer Chemother Pharmacol 52: 391-398, 2003.

7. Noguchi T, Ichii S, Morisada S, Yamaoka T and Yanagi Y: Tumor-selective distribution of an active metabolite of the 9aminoanthracycline amrubicin. Jpn J Cancer Res 89: 1061-1066, 1998.

8. Yamauchi S, Kudoh S, Kimura T, Hirata K and Yoshikawa J: Additive effects of amrubicin with cisplatin on human lung cancer cell lines. Osaka City Med J 48: 69-76, 2002.

9. Morisada S, Yanagi Y, Noguchi T, Kashiwazaki Y and Fukui M: Antitumor activities of a novel 9-aminoanthracycline (SM-5887) against mouse experimental tumors and human tumor xenografts. Jpn J Cancer Res 80: 69-76, 1989.

10. Yoshimura T, Matsushima K, Tanaka S, Robinson EA, Appella E, Oppenheim JJ and Leonard EJ: Purification of a human monocyte-derived neutrophil chemotactic factor that has peptide sequence similarity to other host defense cytokines. Proc Natl Acad Sci USA 84: 9233-9237, 1987.

11. Baggiolini M, Dewald B and Moser B: Interleukin-8 and related chemotactic cytokines - CXC and CC chemokines. Adv Immunol 55: 97-179, 1994.

12. Furutani Y, Nomura H, Notake M, Oyamada Y, Fukui T, Yamada M, Larsen CG, Oppenheim JJ and Matsushima K: Cloning and sequencing of the cDNA for human monocyte chemotactic and activating factor (MCAF). Biochem Biophys Res Commun 159: 249-255, 1989.

13. Montovani A, Sozzani S, Proost P and van Damme J: The monocyte chemoattractant protein family. In Chemoattractant Ligands and their Receptors: Pharmacology and Toxicology: Basic and Clinical Aspects. Horuk R (ed). CRC Press, Boca Raton, FL, pp169-192, 1996.

14. Mosmann T: Rapid colorimetric assay for cellular growth and survival: application to proliferation and cytotoxicity assays. J Immunol Methods 65: 55-63, 1983.

15. Niiya K, Nsimba M, Hayashi T and Sakuragawa N: Downregulation of urokinase secretion from a human lymphoma cell line RC-K8 by dexamethasone without inducing plasminogen activator inhibitors. Thromb Res 65: 311-321, 1992.

16. Granelli-Piperno A and Reich E: A study of proteases and protease-inhibitor complexes in biological fluids. J Exp Med 148: 223-234, 1978.

17. Sambrook J, Fritsh EF and Maniatis T: Molecular Cloning, A Laboratory Manual. 2nd edition, Cold Spring Harbor Laboratory, pp7-39, 1989 .

18. Terada N, Hamano N, Nomura T, Numata T, Hirai K, Nakajima T, Yamada H, Yoshie O, Ikeda-Ito T and Konno A: Interleukin-13 and tumour necrosis factor-alpha synergistically induce eotaxin production in human nasal fibroblasts. Clin Exp Allergy 30: 348-355, 2000.

19. Dulkys Y, Schramm G, Kimmig D, Knoss S, Weyergraf A, Kapp A and Elsner J: Detection of mRNA for eotaxin-2 and eotaxin-3 in human dermal fibroblasts and their distinct activation profile on human eosinophils. J Invest Dermatol 116: 498-505, 2001.
20. Hoeck $\mathbf{J}$ and Woisetschlager M: Activation of eotaxin-3/CCL126 gene expression in human dermal fibroblasts is mediated by STAT6. J Immunol 167: 3216-3222, 2001.

21. Tokunaga K, Nakamura Y, Sakata K, Fujimori K, Ohkubo M, Sawada K and Sakiyama S: Enhanced expression of a glyceraldehyde-3-phosphate dehydrogenase gene in human lung cancers. Cancer Res 47: 5616-5619, 1987.

22. Niiya M, Niiya K, Shibakura M, Asaumi N, Yoshida C, Shinagawa K, Teshima T, Ishimaru F, Ikeda $K$ and Tanimoto $M$ : Involvement of ERK1/2 and p38 MAP kinase in doxorubicininduced UPA expression in human RC-K8 lymphoma and NCIH69 small cell lung carcinoma cells. Oncology 67: 310-319, 2004.

23. Lampinen M, Carlson M, Hakansson LD and Venge P: Cytokine-regulated accumulation of eosinophils in inflammatory disease. Allergy 59: 793-805, 2004.

24. Kitaura M, Suzuki N, Imai T, Takagi S, Suzuki R, Nakajima T, Hirai K, Nomiyama $\mathrm{H}$ and Yoshie O: Molecular cloning of a novel human CC chemokine (Eotaxin-3) that is a functional ligand of CC chemokine receptor 3. J Biol Chem 274: 27975-27980, 1999.

25. Shinkai A, Yoshisue H, Koike M, Shoji E, Nakagawa S, Saito A, Takeda T, Imabeppu S, Kato Y, Hanai N, et al: A novel human CC chemokine, eotaxin-3, which is expressed in IL-4-stimulated vascular endothelial cells, exhibits potent activity toward eosinophils. J Immunol 163: 1602-1610, 1999.

26. Daugherty BL, Siciliano SJ, De Martino JA, Malkowitz L, Sirotina A and Springer MS: Cloning, expression, and characterization of the human eosinophil eotaxin receptor. J Exp Med 183: 2349-2354, 1996.

27. Uguccioni M, Mackay CR, Ochensberger B, Loetscher P, Rhis S, LaRosa GJ, Rao P, Ponath PD, Baggiolini M and Dahinden CA: High expression of the chemokine receptor CCR3 in human blood basophils. Role in activation by eotaxin, MCP-4, and other chemokines. J Clin Invest 100: 1137-1143, 1997.

28. Gerber BO, Zanni MP, Uguccioni M, Loetscher M, Mackay CR, Pichler WJ, Yawalkar N, Baggiolini M and Moser B: Functional expression of the eotaxin receptor CCR3 in T lymphocytes colocalizing with eosinophils. Curr Biol 7: 836-843, 1997.

29. Uston PI and Lee CM: Characterization and function of the multifaceted peripheral blood basophil. Cell Mol Biol 49: 1125-1135, 2003.

30. Yssel $\mathrm{H}$ and Groux $\mathrm{H}$ : Characterization of $\mathrm{T}$ cell subpopulations involved in the pathogenesis of asthma and allergic diseases. Int Arch Allergy Immunol 121: 10-18, 2000.

31. Norman PS: Immunotherapy: 1999-2004. J Allergy Clin Immunol 113: 1013-1024, 2004.

32. De Paulis A, Montuori N, Prevete N, Fiorentino I, Rossi FW, Visconte V, Rossi G, Marone G and Ragno P: Urokinase induces basophil chemotaxis through a urokinase receptor epitope that is an endogenous ligand for formyl peptide receptor-like 1 and -like 2. J Immunol 173: 5739-5748, 2004.

33. Nakajima H, Gleich GJ and Kita H: Constitutive production of IL- 4 and IL-10 and stimulated production of IL- 8 by normal peripheral blood eosinophils. J Immunol 156: 4859-4866, 1996 .

34. Yousefi S, Hemmann S, Weber M, Holzer C, Hartung K, Blaser K and Simon HU: IL-8 is expressed by human peripheral blood eosinophils. Evidence for increased secretion in asthma. J Immunol 154: 5481-5490, 1995. 